\title{
Identification of Risk Factors and Cross-Reactivity of Local Anesthetics Hypersensitivity: Analysis of I4-Years' Experience
}

This article was published in the following Dove Press journal: Journal of Asthma and Allergy

\author{
Ilkay Koca Kalkan' \\ Gozde Koycu Buhari' \\ Hale Ates' \\ Buket Basa Akdogan' \\ Ozlem Erdem Ozdedeoglu' \\ Kurtulus Aksu' \\ Ferda Oner Erkekol ${ }^{2}$ \\ 'Department of Immunology and Allergy, \\ Atatürk Chest Diseases and Thoracic \\ Surgery Training and Research Hospital, \\ Ankara, Turkey; ${ }^{2}$ Division of Immunology \\ and Allergy, Department of Chest \\ Diseases, Ankara Yıldırım Beyazıt \\ University School of Medicine, Ankara, \\ Turkey
}

Purpose: Local anesthetics (LA) are widely used and adverse drug reactions (ADR) occur in $2.5-10 \%$, but hypersensitivity reactions are rare (ranging between $0 \%$ and $4.3 \%$ ). Risk is so overestimated causing too many allergy clinic referrals. There are limited and also conflicting results over the management of LA allergy. We aimed to find out who should be referred to an allergy clinic for a LA allergy testing, to define the subjects with an increased risk of LA allergy and to assess the need for testing for identifying alternative LA. Patients and Methods: We performed a retrospective study of patients referred to our clinic for diagnostic workup of LA hypersensitivity from 2006 to 2020.

Results: In our cohort of 398 patients, tests were positive in 14 (3.52\%) of them. Personal history of ADR with LA was the only independent risk factor for positive test $(R R=4.007$, $\mathrm{p}=0.033$ ). Presence of generalized cutaneous symptoms and hypotension during past reaction were independent predictors of positive test $(R R=9.043, p=0.021$ and $R R=10.445, p=0.038$, respectively). The negative predictive value of intradermal test at dilution of 1:100 for immediate-type reaction was high $(97.56 \%)$. Also, we demonstrated cross-reactivity within the amide-group LAs and co-occurrence of immediate- and delayed-type reactions.

Conclusion: Only patients with an LA-induced ADR should be referred to an allergy clinic. History of generalized cutaneous symptoms and/or hypotension during the reaction may define subjects with an increased risk of LA allergy. A stepwise test procedure may start with skin tests especially for these patients with increased risk factors. In presence of LA allergy, alternative LA should always be confirmed by performing a challenge test.

Keywords: intradermal tests, local anesthetics, drug hypersensitivity, skin tests, risk factors, prick tests

\section{Introduction}

Local anesthetic (LA) agents have been widely used since the late 19th century. Nowadays, it is estimated that worldwide 6 million doses of LAs are administrated daily. ${ }^{1}$

Local anesthetics are chemically composed of three parts, an aromatic ring connected by an ester or amide link to a secondary or tertiary amine function. According to this structure they are classified into benzoic acid esters (piperocaine, benzocaine, chloroprocaine, procaine, tetracaine, cocaine) or amide derivatives (mepivacaine, lidocaine, bupivacaine, articaine, ropivacaine, prilocaine). ${ }^{2}$

Adverse drug reactions (ADR) to LAs have been estimated to occur in $2.5-10 \%$ of the patients. ${ }^{3}$ Although the first allergic reaction was reported as back as 1920 ,
Correspondence: Illkay Koca Kalkan Department of Immunology and Allergy, Atatürk Chest Diseases and Thoracic Surgery Training and Research Hospital, Sanatoryum Cad, Keçiören, Ankara 06280, Turkey

Tel +90505 3II77I0

Fax +903123552110

Email ilkay.koca@gmail.com
Journal of Asthma and Allergy 2021:14 47-58 
a contact dermatitis caused by an ester-type local anesthetic agent, the vast majority of the ADRs are nonimmunologic reactions like toxicity, intravascular administration of LA, overdosage of LA, anxiety (needle phobia, panic attacks, vasovagal syncope) and the pharmacological effect of added vasopressors (eg adrenaline)., ${ }^{4,5}$ Hypersensitivity reactions are rare and thought to represent less than $1 \%$ of all ADRs. Allergic reactions to LAs can manifest as immediate IgE mediated (type I) and/or non-immediate T-cell mediated (type IV). ${ }^{6}$ While type I reactions are exceedingly rare and can cause anaphylaxis, type IV reactions are relatively common, mostly presented as allergic contact dermatitis, and are not life-threatening for the patient. ${ }^{7}$

Most of the time differentiating between allergic and nonallergic ADRs can be difficult because of the overlap of symptoms in LAs. When the diagnosis of drug hypersensitivity is based on history alone, the result is unreliable. Even though LAs are infrequent causes of allergic reactions, sometimes the risk is still so overestimated by health-care professionals from other disciplines and by patients that, even in the absence of a history of ADR to LAs, the cases with other allergic comorbidities avoid using LAs causing unnecessarily painful procedures. In some cases, general anesthesia is administered instead at increased risk to the patient. ${ }^{8}$ In two recent studies with retrospective periods of 5 and 10 years, none of the total 326 patients with suspected immediate allergy to LAs reacted-on provocation tests. ${ }^{1,9}$ But at the other end of the scale, one must keep in mind that such genuine hypersensitivity reactions to LA may occur and cannot be denied. The literature review by Bhole et al assessed 23 series of cases that included 2978 patients and revealed 29 patients with type 1 hypersensitivity reaction to LAs, confirming the reported prevalence of LA allergy in large series to be $<1 \%(0.97 \%){ }^{6}$

Considering both the rarity and the risk of allergic reactions to LAs, an appropriate approach on the selection of patients for investigation is needed, since LA skin tests and challenges to determine the allergy are painful, timeconsuming and costly procedures. The current level of knowledge does not allow clinicians to predict which patients will present with a hypersensitivity reaction to LAs. The literature reports are few and data on the consideration concerns of the test indications are controversial. Saito et al suggested LAs have high risks of allergy development in patients with an overall allergic tendency to any of drugs, foods, and diseases. ${ }^{10}$ While others recommended no tests in the absence of previous adverse reactions showing signs and symptoms suggestive of hypersensitivity reaction. ${ }^{11,12}$ Also, there are no generally accepted parameters from the case history of past reaction with LAs predicting a positive test outcome. While some studies reported skin symptoms such as itch, generalized urticaria, flushing and/or respiratory and circulatory symptoms as indicatives of an allergic reaction, others found no predictive parameter. ${ }^{1,13,14}$ Besides, there is no common agreement for the appropriate workup for these patients. EAACI/ENDA guideline recommends skin prick test with neat LA and intradermal test with $1 / 10$ dilution of LA followed by subcutaneous provocation test. ${ }^{15}$ But some advocate the use of a 1:100 dilution for intradermal testing to minimize irritant test reactions, while others believe that intradermal tests may be omitted because false-positive test results to LAs do occur. ${ }^{7,16,17}$ On the other hand, since allergy to LAs is rare Furci et al suggested that a negative skin test can exclude an IgE-mediated hypersensitivity reaction and Kvisselgaard et al suggested that most patients can be managed using a single full-dose placebo-controlled subcutaneous provocation with the culprit LA without prior skin testing. ${ }^{1,18}$ The existence and pattern of cross-reactivity between LAs is still not clear, since these reactions are limited to case reports and findings were inconsistent. ${ }^{2,17,19-21}$

Based on these conflicting results, the main aims of our study were therefore 1) to find out who should be referred to an allergy clinic for an LA allergy testing; 2) to define the subjects with an increased risk of LA allergy; 3) to verify the appropriate workup protocol for diagnosing LA allergy; and 4) to assess the existence of cross-reactivity among LAs and the need for a test to identify an alternative LA.

\section{Patients and Methods \\ Study Population}

A retrospective medical record review was performed on all patients referred to our allergy clinic for diagnostic workup of local anesthetic hypersensitivity during a 14year period from 2006 to 2020. The study was approved by the Ankara Kecioren Educational Research Hospital Clinical Research Ethics Committee (24.06.2020/2122). Informed consent was waived due to the retrospective nature of this study, along with no modifications in patient management. All personal information was encrypted in the database, and patient data accessed was de-identified. There was no breach of privacy. All procedures performed 
in this study involving human participants were in accordance with the 1964 Helsinki declaration and its later amendments.

Demographic characteristics of the patients were collected from case files. No assumptions or clinical interpretations were made about information not specifically mentioned. Data collection included documentation of age, gender, presence of atopy, the reason for referral, presence of any allergic disorders, history of LA allergy and/or drug hypersensitivity reaction (DHR) to drugs other than LAs. Additional information was recorded in case of an existing history of reaction with LA; like name of the incriminated LA, the number of LA reactions, latency time from LA administration to the first symptom, time interval from the last reaction to follow up and clinical complaints/symptoms distributed to six organ systems (skin, upper respiratory, lower respiratory, cardiovascular, gastrointestinal, central nervous system). In patients with more than one LA reaction history, the most recent episode was included.

\section{Diagnostic Tests}

At the time of testing, the patients were free of clinically relevant cutaneous, respiratory or any other symptoms. Informed consents of the patients were obtained before tests. Vital signs, skin response and spirometry findings were obtained at baseline, and monitored throughout and after the tests. The patients had peripheral intravenous catheters in place at the start. A nurse and a doctor attended during testing. Equipment and personnel for emergency resuscitation were present during all tests. Medications, especially antihistamines, that can interfere with allergy tests were stopped prior to tests according to guidelines. ${ }^{22}$

All tests were carried out with vasoconstrictor-free preparation of that LA. At the outset, testing with the offending agent was aimed, but in cases in which the culprit drug was unknown, vasoconstrictor-free preparation of suspected LA was not available or the patient did not accept a diagnostic test, an alternative agent was tested. For that preservative-free, single-dose vials were preferred (like lidocaine and mepivacaine) or an LA requested by the consultant was tested. Only for prilocaine, we had to use adjuvant containing (methylparaben) preparation.

\section{Prick and Intradermal Skin Testing}

Skin tests were performed by trained allergy nurses according to the guidelines. ${ }^{22,23}$ Skin-prick testing (SPT) was performed on the volar surface of the forearm with undiluted LA, a positive (Histamine chloride $10 \mathrm{mg} / \mathrm{mL}$ ) and negative control (phenolated glycerol-saline). The skin test sites were read after 15 minutes. A positive SPT was defined as a wheal $3 \times 3 \mathrm{~mm}$ or greater. A negative SPT was followed by an intradermal test (IDT) with a 1/100 diluted LA. The IDT was also examined after 15 minutes. IDT was considered as positive when the size of the initial wheal diameter increases by $3 \mathrm{~mm}$ or greater. If this was negative too, the subject proceeded to subcutaneous provocation testing.

\section{Subcutaneous Provocation Testing (SCPT)}

Subcutaneous undiluted LA injections were administered every 30-minute at incremental volumes of $0.1 \mathrm{~mL}$, $0.5 \mathrm{~mL}$ and $1 \mathrm{~mL}$ into the upper arm. The subcutaneous injection site was examined after 30 minutes, if the test was negative next concentration was given at a different location. A provocation was considered positive on the development of objective allergy symptoms, which is, skin symptoms (rash/swelling) and/or systemic symptoms (respiratory/circulatory). All patients remained in the hospital under medical supervision for 2 hours after each challenge and were re-examined in the clinic the next day to determine whether any late reactions had occurred after discharge. If symptom appears $>6$ hours after provocation, the reaction is classified as a delayedtype reaction, otherwise immediate-type reaction.

Only one LA was tested per day. Intradermal test dilution is prepared freshly in a sterile syringe using a sterile solution of the suspected drug in sterile $0.9 \%$ saline. Otherwise, the allergens are used freshly from the LAs vial. The vials are opened no longer than $2 \mathrm{~h}$ preceding last dose administration.

\section{Statistical Method}

Statistical Package for the Social Sciences (SPSS) version 25 (SPSS, Chicago, IL) was used for the statistical analysis of this study. Descriptive statistics (frequencies, means, and standard deviations, median and minimum-maximum) were calculated. The univariate analyses to identify variables associated with LA skin/provocation test outcome were investigated using Chi-square, Fisher exact, Student's $t$-test and Mann-Whitney $U$-tests, where appropriate. For the multivariate analysis, the possible factors identified with univariate analysis were further entered into the binary logistic regression analysis to determine independent 
predictors of patient outcome. A p-value $<0.05$ was considered statistically significant.

\section{Results}

\section{Study Population}

A total of 488 LA provocation tests in 430 patients were performed in our allergy clinic during the last 14 years. Thirty-two patients with 36 tests were excluded because of their incomplete medical records (Figure 1). The rest 398 patients (310 women/88 men, mean age $42.35 \pm 11.81$ years) were tested with 452 provocations to LA.

Patients were most commonly consulted by dentists (246, $62.1 \%)$, followed by anesthesiologists (42, 10.6\%). Occasionally self-referred patients $(84,21.2 \%)$ were also evaluated (Table 1). The most common referral reason was having a DHR other than LAs $(216,54.3 \%)$. It was followed by a past reaction with LAs $(142,35.7 \%)$ (Figure 2). Also, $133(33.4 \%)$ patients described allergic reactions with multiple different drug groups (MDH) (Table 1). Of the patients with a history of suspected DHR to LA, only half of the cases incriminated LA was known. Among the recognized LAs, articaine was the most proclaimed $(32,22.5 \%)$ drug (Table 2).

\section{Local Anesthetic Test results and Characteristics of the Patients}

Lidocaine was the most frequently tested (248, 54.87\%) LA, followed by mepivacaine $(95,21.01 \%)$ and prilocaine $(87,19.25 \%)$. Most of the cases were tested with only one

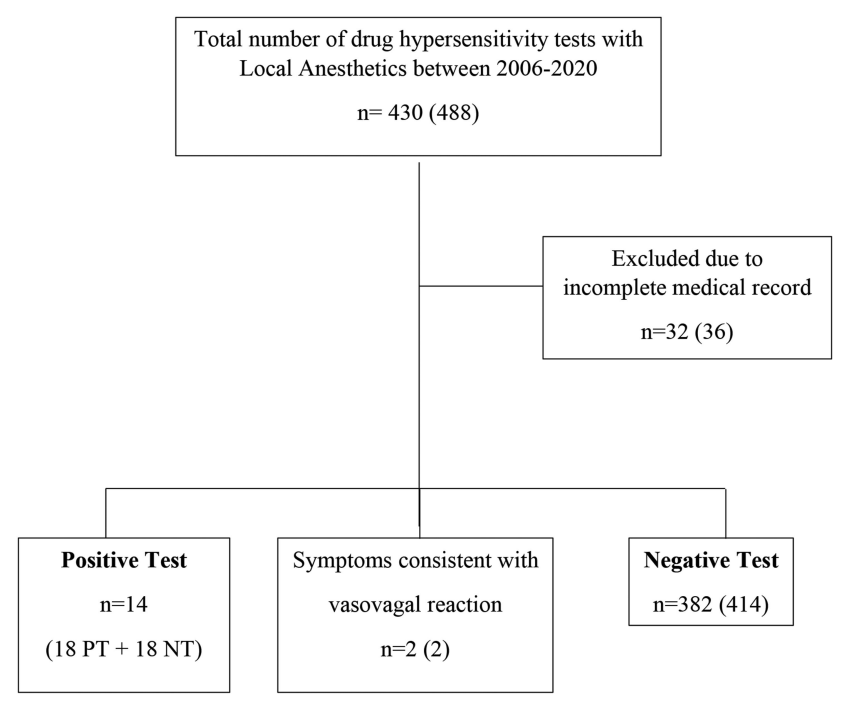

Figure I Study flowchart; evaluation of patients referred to our allergy clinic for diagnostic workup of local anesthetics hypersensitivity.

Abbreviations: $n$, number of patients; (n), number of drugs tested; PT, positive drug test; NT, negative drug test.
LA (353, 88.7\%). Additional LAs were tested according to the patient's history ( 1 additional LA in 38 cases, 2 additional LA in 5 cases, 3 additional LA in 2 cases). Of these cases, only 10 of them could be tested with the culprit LA, either because vasoconstrictor-free preparation of that LA was not available or the patients did not give consent.

In the total of the 398 cases tested with 452 LA skin/ provocation tests, 14 patients had 18 positive tests. No anaphylactic reactions were observed during tests. When we compare these 398 cases, according to their test results, female gender and personal history of DHR with LA were significantly more seen in test positive group ( $p$-values were 0.042 and 0.004 , respectively) (Table 1). But there was no statistically significant difference between two groups according to the presence of concomitant asthma, chronic urticaria + angioedema $(\mathrm{CU} \pm \mathrm{AE})$, personal history of other drug allergies or allergic diseases, atopy or age. Binary logistic regression analysis indicated that the personal history of DHR with LA was the only independent predictor of positive LA skin/provocation test $(R R=4.007$, $\mathrm{p}=0.033)$ (Table 3).

\section{Subgroup Analyses of Patients with a History of DHR to LAs}

Since the personal history of DHR with LA is the only independent risk factor, we performed a subgroup analysis with those 142 cases. We compared the clinical characteristics of LA-allergic patients with LA-nonallergic patients in this patient group (Table 4). LA-allergic patients were all female and statistically younger than LA-nonallergic patients ( $p$-values were 0.149 and 0.017 , respectively). Data like the number of LA reactions, time between the last reaction to the follow-up and latency time from LA administration to first symptom were comparable between the two groups. Considering the cases based on symptoms; LA-allergic patients were significantly more likely to have generalized cutaneous symptoms, a combination of pallor-sweating-heat sensation-chills and hypotension ( $p$-values were $0.015,0.041$ and 0.024 , respectively). None of the LA-allergic patients reported lower respiratory symptoms. There was no significant difference in the personal history of allergic diseases, DHR other than LA or MDH. Binary logistic regression analysis indicated that having a history of generalized cutaneous symptoms and hypotension during an LA reaction were independent predictors of a positive LA skin/provocation test $(\mathrm{RR}=9.043, \mathrm{p}=0.021$ and $\mathrm{RR}=10.445, \mathrm{p}=0.038$, respectively) (Table 5). 
Table I Demographic and Clinical Characteristics of the Study Population, Who Were Referred for Assessment of Local Anesthetic Hypersensitivity, Compared in Terms of Drug Test Results with Local Anesthetic

\begin{tabular}{|c|c|c|c|c|}
\hline & \multirow[t]{2}{*}{ Total } & \multicolumn{2}{|c|}{ Local Anesthetic Test } & \multirow[t]{2}{*}{$p$} \\
\hline & & + & - & \\
\hline Gender (female/male), n (\%) & $310(77.9) / 88(22.1)$ & $14(100) / 0$ & $296(77.1) / 88(22.9)$ & 0.042 \\
\hline Age, mean (士SD) & $42.35(I I .8 I)$ & $39.07(9.54)$ & $42.47(11.88)$ & 0.291 \\
\hline Atopy, $n( \pm)$ & $53 / 145$ & $3(42.9) / 4(57.1)$ & $50(26.2) / / 4 \mid(73.8)$ & 0.328 \\
\hline \multicolumn{5}{|l|}{ Consultation requested by, $\mathrm{n}(\%)$} \\
\hline Dentistry & $246(62.1)$ & $12(85.8)$ & $234(6 \mid .3)$ & 0.238 \\
\hline Anesthesiology & $42(10.6)$ & 0 & $42(11)$ & \\
\hline Self-admission & $84(2 \mid .2)$ & I (7.I) & $83(21.7)$ & \\
\hline Other & $24(6.1)$ & I (7.I) & $23(6)$ & \\
\hline \multicolumn{5}{|l|}{ Allergic comorbidities, $\mathbf{n}$ (\%) } \\
\hline Asthma & $69(17.5)$ & $3(21.4)$ & $66(17.3)$ & 0.691 \\
\hline $\mathrm{CU} \pm$ Angioedema & $51(12.9)$ & 0 & $51(13.4)$ & 0.142 \\
\hline Latex hypersensitivity & $3(0.8)$ & I (7.I) & $2(0.5)$ & 0.103 \\
\hline Other & $48(12.2)$ & $3(2 \mid .4)$ & $45(11.8)$ & 0.393 \\
\hline Total & $138(34.9)$ & $4(28.6)$ & $134(35.2)$ & 0.778 \\
\hline Personal history of DHR with LA, n (\%) & $142(35.7)$ & $10(71.4)$ & $132(34.4)$ & 0.004 \\
\hline \multicolumn{5}{|c|}{ Personal history of DHR other than LA, $n$ (\%) } \\
\hline Antibiotics & $137(34.4)$ & $2(14.3)$ & $135(35.5)$ & 0.101 \\
\hline NSAID & $172(43.8)$ & $4(28.6)$ & $168(44.3)$ & 0.243 \\
\hline Muscle relaxant & $18(4.6)$ & 0 & $18(4.7)$ & 0.405 \\
\hline Radiocontrast agent & $7(1.8)$ & 0 & $7(1.8)$ & 0.608 \\
\hline General anesthetics & $20(5.1)$ & I (7.I) & $19(5)$ & 0.720 \\
\hline Other & $40(10.2)$ & I (7.I) & $39(10.3)$ & 0.704 \\
\hline Total & $272(68.9)$ & $7(50)$ & $265(69.6)$ & 0.121 \\
\hline Personal history of MDH, n (\%) & $133(33.4)$ & $5(35.7)$ & 128 & 0.886 \\
\hline
\end{tabular}

Abbreviations: $\mathrm{CU}$, chronic urticaria; DHR, drug hypersensitivity reaction; LA, local anesthetic; MDH, multiple drug hypersensitivity; NSAID, nonsteroidal antiinflammatory drugs.

\section{Local Anesthetic Allergic Cases}

Clinical data and diagnostic test results of the 14 patients (3.52\%) with 18 positive LA IDT/SCPT results are shown in Table 6. Of 18 positive test results, 7 of them were positive for IDTs with 1:100 dilution of the drugs. Although all the remaining 11 tests resulted with allergic reactions with SCPTs after negative IDTs. All of the patients with LA DHR history had claimed an immediatetype reaction, but two delayed-type reactions were observed during SCPTs. Since SCPTs are considered to be the gold standard for confirmation of true IgE-mediated allergy, after omitting two delayed-type reactions from the test series, the calculated negative predictive value of IDT at LA dilutions of 1:100 for immediate-type reaction was 97.56\% (CI 96.89-98.67\%). Lidocaine represented the most common LA with positive test results $(n=9)$, followed by mepivacaine $(\mathrm{n}=5)$, prilocaine $(\mathrm{n}=3)$ and bupivacaine $(n=1)$. Three patients demonstrated cross-reactivity within the amide group, Patient no. 4 was tested positive to both lidocaine and bupivacaine, no. 5 was tested positive to lidocaine and mepivacaine, while no. 10 was tested positive to all three: lidocaine, mepivacaine and prilocaine.

\section{Discussion}

In our cohort of 398 patients, who were referred to our clinic for allergy workup because of alleged LA hypersensitivity, test results were positive in $3.5 \%$. The only independent predictors of a positive LA skin/provocation test were the personal history of DHR with LA and having generalized cutaneous symptoms and hypotension during this past LA reaction. The negative predictive value of IDT (at a dilutions of 1:100) for immediate-type reaction 


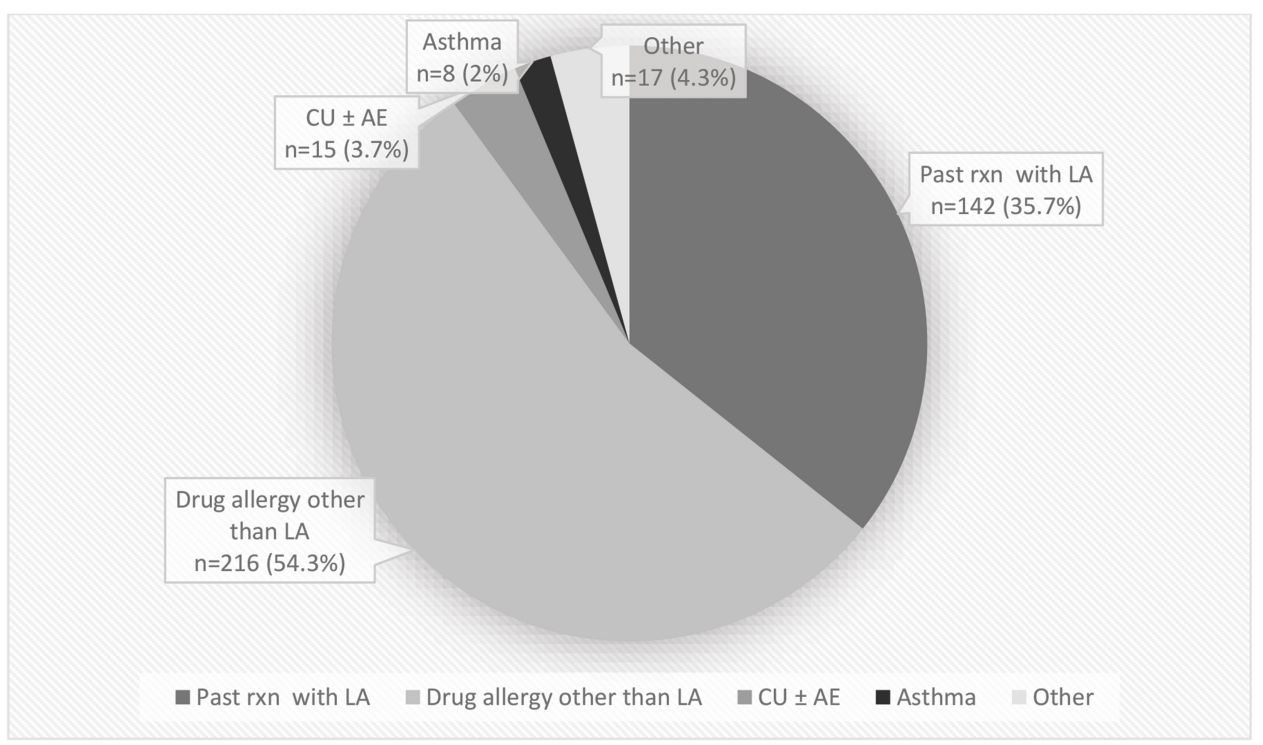

Figure 2 Primary reason for referral for diagnostic workup of local anesthetics (LA) hypersensitivity.

Abbreviation: $n$, number of patients; $C U \pm A E$, chronic urticaria \pm angioedema; rxn, reaction.

was high (97.56\%). The presence of cross-reactivity within the amide group LAs and co-occurrence of immediate- and delayed-type reactions were also demonstrated.

Table 2 Documentation of Findings of Local Anesthetic Hypersensitivity

\begin{tabular}{|c|c|c|c|}
\hline & \multirow[t]{2}{*}{ Total } & \multicolumn{2}{|c|}{$\begin{array}{l}\text { Local Anesthetic } \\
\text { Test }\end{array}$} \\
\hline & & + & - \\
\hline \multicolumn{4}{|l|}{ Incriminated LA, n (\%) } \\
\hline Lidocaine & $28(19.8)$ & $\mathrm{I}(\mathrm{I0})$ & $27(20.5)$ \\
\hline Prilocaine & $7(4.9)$ & I (I0) & $6(4.5)$ \\
\hline Articaine & $32(22.5)$ & $6(60)$ & $26(19.6)$ \\
\hline Bupivacaine & $3(2.1)$ & 0 & $3(2.3)$ \\
\hline Procaine & $\mathrm{I}(0.7)$ & 0 & $\mathrm{I}(0.8)$ \\
\hline Unknown & $71(50)$ & $2(20)$ & $69(52.3)$ \\
\hline \multicolumn{4}{|l|}{ Tested LA per patient, $n$} \\
\hline I Test & $353(88.7)$ & 0 & 353 \\
\hline 2 Tests & $38(9.5)$ & 8 & 30 \\
\hline 3 Tests & $5(1.3)$ & 4 & I \\
\hline 4 Tests & $2(0.5)$ & 2 & 0 \\
\hline Diagnostic test & 10 & I & 9 \\
\hline LA test reactions, $\mathbf{n}(\%)$ & & + & - \\
\hline Lidocaine & $248(54.87)$ & 9 & 239 \\
\hline Mepivacaine & $95(21.01)$ & 5 & 90 \\
\hline Prilocaine & $87(19.25)$ & 3 & 84 \\
\hline Bupivacaine & $13(2.88)$ & 1 & 12 \\
\hline Articaine & $9(1.99)$ & 0 & 9 \\
\hline Total & $452(100)$ & $18(3.98)$ & $434(96.02)$ \\
\hline
\end{tabular}

To the best of our knowledge, this is one of the largest series in English literature, and below we discuss these results comparing with other studies.

Exposure to LA is almost inevitable during a lifetime. True allergy to LAs is considered exceptional among allergy experts. Earlier studies suggest an incidence of immediate allergy to LAs in the range of $0 \%$ to $4.3 \%$ after allergy investigation. ${ }^{1,9,12}$ But the risk is still overestimated by other health-care workers and not least by patients leading to unnecessary avoidance of LAs or too many allergy clinic referrals. It is our everyday experience to deal with increasing numbers of patients referred for allergy workup before pending LA exposure, even without any history of suspected LA reaction. More than $60 \%$ of our patients were referred by dentists, most commonly with the referral reason for having a DHR other than LAs (54.3\%). This was comparable with

Table 3 Multivariate Analysis to Identify Independent Risk Factors Associated with Local Anesthetic Hypersensitivity in All Patients Referred to Our Allergy Clinic for Assessment $(n=398)$

\begin{tabular}{|l|l|l|}
\hline Variables & $\begin{array}{l}\text { Relative Risk } \\
(\mathbf{9 5 \%} \mathbf{C l})\end{array}$ & $\mathbf{P}$ \\
\hline $\begin{array}{l}\text { Personal history of DHR with } \\
\text { NSAID }\end{array}$ & $0.888(0.246-3.202)$ & 0.856 \\
$\begin{array}{l}\text { Personal history of DHR with } \\
\text { antibiotics }\end{array}$ & $0.404(0.087-1.887)$ & 0.249 \\
Personal history of DHR with LA & $4.007(1.115-14.397)$ & 0.033 \\
\hline
\end{tabular}

Abbreviations: $\mathrm{Cl}$, confidence interval; $\mathrm{CU}$, chronic urticaria; $\mathrm{DHR}$, drug hypersensitivity reaction; LA, local anesthetic; NSAID, nonsteroidal anti-inflammatory drugs. 
Table 4 Demographic and Clinical Characteristics of 142 Patients with Personal History of Suspected Local Anesthetic Hypersensitivity

\begin{tabular}{|c|c|c|c|}
\hline & \multicolumn{2}{|c|}{ Local Anesthetic Test } & \multirow[t]{2}{*}{$\mathbf{p}$} \\
\hline & + & - & \\
\hline Gender (female/male), n (\%) & $10(100) / 0$ & $109(82.6) / 23(17.4)$ & 0.149 \\
\hline Age, mean ( \pm SD) & $37(6.22)$ & $42.99(11.93)$ & 0.017 \\
\hline Atopy, $\mathrm{n} \pm(\%)$ & I (25)/3 (75) & $14(2 \mid .2) / 52(78.8)$ & I \\
\hline Number of LAH reactions, median (min-max) & $I(I-2)$ & $I(I-6)$ & 0.453 \\
\hline Time interval from last reaction to follow-up months, median (min-max) & $6.5(I-120)$ & II.5 (I-240) & 0.435 \\
\hline Latency time from LA administration to first symptom & & & 0.915 \\
\hline $0-30 \min$ & $6(60)$ & $82(62.2)$ & \\
\hline $31-120 \mathrm{~min}$ & $2(20)$ & $17(12.9)$ & \\
\hline $2-6 \mathrm{hr}$ & $\mathrm{I}(\mathrm{I0})$ & $9(6.8)$ & \\
\hline $6-24 \mathrm{hr}$ & - & $6(4.5)$ & \\
\hline$>24 \mathrm{hr}$ & - & $6(4.5)$ & \\
\hline Unknown & $\mathrm{I}(\mathrm{I0})$ & $12(9.1)$ & \\
\hline \multicolumn{4}{|l|}{ Symptoms } \\
\hline Cutaneous, n (\%) & $8(80)$ & $79(60.8)$ & 0.227 \\
\hline Local/Generalized reaction & $2(20) / 6(60)$ & $48(50) / 23(24)$ & 0.015 \\
\hline Pruritus, paresthesia & $I(10)$ & $17(13.1)$ & 0.779 \\
\hline PSHC & $3(30)$ & $12(9.2)$ & $0.04 I$ \\
\hline Flushing, erythema & $4(40)$ & $25(19.2)$ & 0.118 \\
\hline $\mathrm{CU} \pm$ Angioedema & $5(50)$ & $43(33.1)$ & 0.277 \\
\hline Upper respiratory, n (\%) & $2(20)$ & $38(29.2)$ & 0.534 \\
\hline Rhinitis & I (I0) & $3(2.3)$ & 0.259 \\
\hline Globus sensation & $\mathrm{I}(10)$ & $38(29.2)$ & 0.191 \\
\hline Itchy throat & $\mathrm{I}(10)$ & $\mathrm{I}(0.8)$ & 0.138 \\
\hline Lower respiratory, n (\%) & 0 & $45(34.6)$ & 0.024 \\
\hline Cough & 0 & $2(1.5)$ & 1 \\
\hline Chest tightness, dyspnea & 0 & $45(34.6)$ & 0.024 \\
\hline Cardiovascular, n (\%) & $2(20)$ & $8(6.2)$ & 0.101 \\
\hline Palpitation, tachycardia & 0 & $3(2.3)$ & 1 \\
\hline Hypotension & $2(20)$ & $5(3.8)$ & 0.024 \\
\hline Gastrointestinal, n (\%) & $\mathrm{I}(10)$ & $9(6.9)$ & 0.716 \\
\hline Abdominal pain & $I(10)$ & 0 & 0.071 \\
\hline Nausea, vomiting & 0 & $9(6.9)$ & 0.390 \\
\hline Central nervous system, $\mathrm{n}(\%)$ & 0 & $29(22.3)$ & 0.093 \\
\hline \multicolumn{4}{|l|}{ Allergic comorbidities, $\mathbf{n}(\%)$} \\
\hline Asthma & 0 & $16(12.2)$ & 0.240 \\
\hline $\mathrm{CU} \pm$ Angioedema & 0 & $9(6.9)$ & 0.392 \\
\hline Other & $\mathrm{I}(\mathrm{I0})$ & $10(7.6)$ & 0.788 \\
\hline Total & $3(30)$ & $45(34.4)$ & 0.780 \\
\hline \multicolumn{4}{|l|}{ Personal history of DHR other than LA, $n$ (\%) } \\
\hline Antibiotics & I (I0) & $31(23.7)$ & 0.320 \\
\hline NSAID & $2(20)$ & $30(23.1)$ & 0.823 \\
\hline Muscle relaxant & 0 & $4(3.1)$ & 1 \\
\hline Radiocontrast agent & 0 & $3(2.3)$ & I \\
\hline
\end{tabular}

(Continued) 
Table 4 (Continued).

\begin{tabular}{|l|l|l|l|}
\hline \multirow{2}{*}{} & \multicolumn{2}{l|}{ Local Anesthetic Test } \\
\cline { 2 - 4 } & + & - & \multicolumn{2}{l|}{$\boldsymbol{P}$} \\
\hline $\begin{array}{l}\text { General anesthetics } \\
\text { Other } \\
\text { Total }\end{array}$ & 0 & $3(2.3)$ & I (10) \\
\hline Personal history of MDH, n (\%) & $4(40)$ & $51(38.9)$ & 0.447 \\
0.947 \\
\hline
\end{tabular}

Abbreviations: CU, chronic urticaria; PSHC, pallor, sweating, heat sensation, chills; LAH, local anesthetic hypersensitivity; NSAID, nonsteroidal anti-inflammatory drugs.

Table 5 Multivariate Analysis of Estimated Effects of Independent Variables on Predicting Local Anesthetic Hypersensitivity in Patients with Personal History of LA Reaction $(n=142)$

\begin{tabular}{|l|l|l|}
\hline Variables & Relative Risk (95\% CI) & $\mathbf{p}$ \\
\hline Age & $0.988(0.914-1.069)$ & 0.767 \\
PSHC & $2.309(0.416-12.804)$ & 0.338 \\
Hypotension & $10.445(1.142-95.514)$ & 0.038 \\
Local/Generalized skin reaction & $9.043(1.396-58.593)$ & 0.021 \\
\hline
\end{tabular}

Abbreviations: $\mathrm{Cl}$, confidence interval; $\mathrm{PSHC}$, pallor, sweating, heat sensation, chills.

Astarita et al and Yilmaz et al results. ${ }^{12,24}$ History of previous ADR with LAs was the second most common cause for referral, but only in $35.7 \%$ of the total. Altogether this shows that patients' shared concerns about the safety of upcoming administration of LAs with their dentist/physician, seem to be the determinative reason for consultation. In our present study, univariate and binary logistic regression analyses revealed that only pre-existing ADR induced by LAs; but not personal history of other drug allergies (not even $\mathrm{MDH}$ ), presence of atopy, concomitant asthma, chronic urticaria, angioedema or any other allergic diseases; is an independent risk factor for a positive LA skin/provocation test. In line with our findings, Haddi et al demonstrated that the risk of adverse reactions to drugs is no greater in atopic subjects. $^{25}$ Grzanka et al supported our findings in their review by suggesting that only the previous appearance of unexpected ADR with LAs may be a risk factor for hypersensitivity reaction to LAs. ${ }^{11}$ Yilmaz et al's study corroborated their recommendation and our result, too. On the other hand, inconsistent with our study, they suggested that MDH history may also be a risk factor; however, this suggestion was not statistically verified in their study. ${ }^{12}$

Subgroup analysis of cases with a personal history of DHR with LA revealed that having a history of generalized cutaneous symptoms and hypotension during an LA reaction were independent predictors of positive LA test. But no other clinic or demographic characteristics could be identified as a risk factor. Trautmann and colleagues supported our finding with their work-up of 402 patients with suspected LA hypersensitivity reactions in 20 years. They diagnosed only two patients with genuine LA allergy, but both had a history of generalized urticaria accompanied by arterial hypotension and tachycardia after LA injections. ${ }^{16}$ Harboe et al noted a considerable overlap in manifestations between test-positive and test-negative groups, though itch, generalized urticaria, and documented hypotension were reported more frequently in cases with positive tests. ${ }^{13}$ But inconsistent with our study Jacobsen et al found no parameter in the case history predicting a positive test outcome. ${ }^{14}$ Taken all together our findings proposed that, within the group of patients with a suspected DHR with LA, a history of generalized cutaneous symptoms and hypotension during a LA reaction appears to identify individuals with a certain degree of risk of LA allergy. But it should be kept in mind that, hypotension also needs to be considered in the differential diagnosis of vasovagal reaction and urticaria in the differential diagnosis of acute urticaria, since its lifetime prevalence is approximately $20 \%{ }^{26}$

The appropriate workup of patients with a history of ADR to LA remains controversial. EAACI/ENDA guideline recommends SCPT of increasing doses up to a therapeutic dosage after a negative SPT done with a neat LA and IDT done with a $1 / 10$ dilution of LA. ${ }^{15}$ For others, IDT may be omitted because the incidence of immediate-type hypersensitivity reaction with LAs is considered extremely low, IDT is a painful procedure for the patients, time-consuming and appears to produce more false-positive reactions than prick tests. ${ }^{1,6}$ The low molecular weight (200-300 Da) of LAs makes them incomplete allergens, known as haptens. Skin testing with the native drug may have a limited value, because haptens need to bind a protein carrier to achieve 


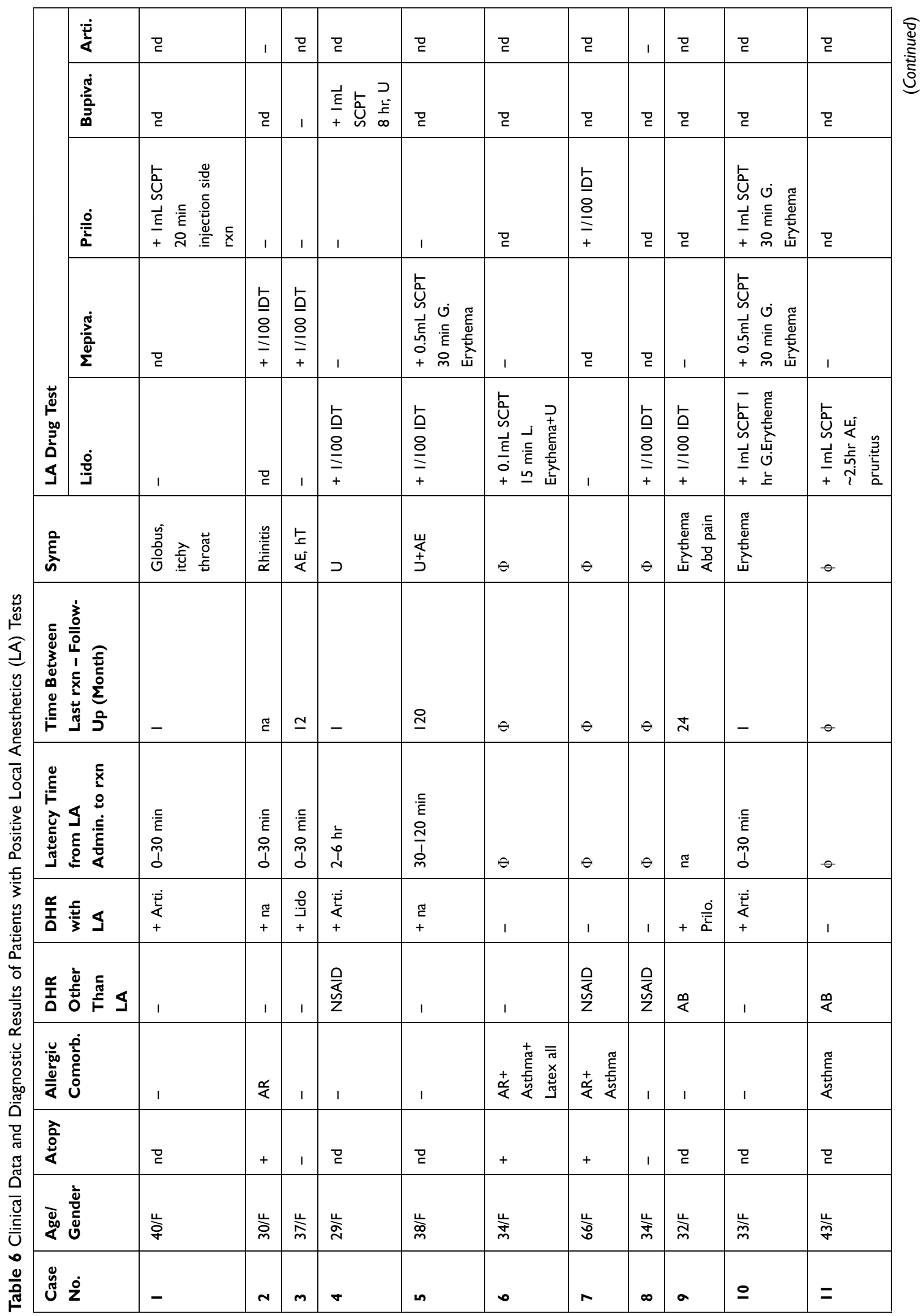




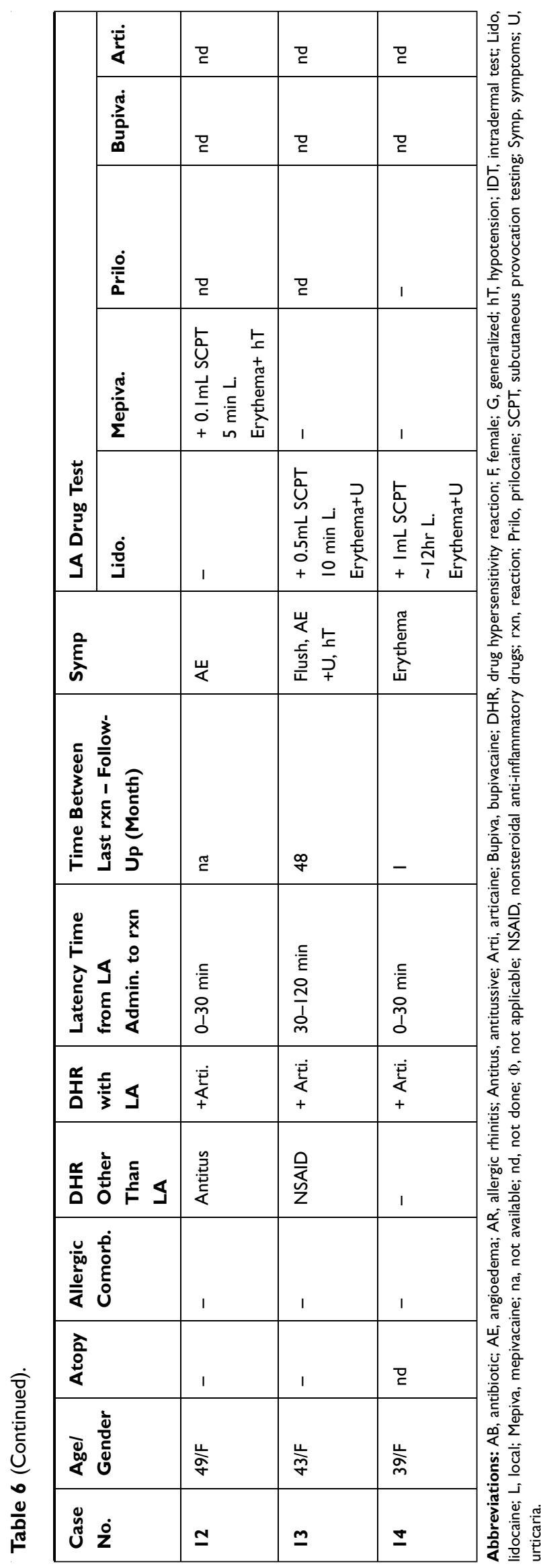

allergenicity, and the allergenic determinant(s) or haptencarrier complex responsible for IgE-mediated allergic reactions to LAs have not been identified. ${ }^{27}$ A low tendency to form such complexes may also explain the low rate of IgEmediated reactions to LAs. Even though advised by the guideline, use of 1/10 dilution for IDT can yield falsepositive results. ${ }^{16,28}$ Trautmann et al calculated diagnostic sensitivity of IDT at LA dilutions of $1: 10,100 \%$, and the specificity $94.5 \% .{ }^{16}$ So, we used the $1 / 100$ dilution for IDT, which may suggest the possibility of true immediate hypersensitivity to the agent tested in line with Trautmann et al and Schatz et al. ${ }^{7,16}$ The full comparison of the sensitivity and specificity of skin tests and SCPT was not possible in our series, as we only selected subjects for provocations that did not yield positive reactions in SPT or IDT. However, we had 11 positive results of SCPT following negative skin tests. So, we found the negative predictive value of the IDT as $97.56 \%$ in accordance with several previous studies. ${ }^{29,30}$ May be in the near future, new alternative methods in the objective evaluation of skin tests, like thermovisiography (a noninvasive imaging technique which can be used to evaluate the body's thermal gradients), will increase their diagnostic specificity and sensitivity.

We here reported one of the largest series of skin tests and challenges and in light of our data, we believe that SPT undiluted and IDT with 1/100 diluted LA are the best starting procedures especially for the patients with increased risk factors, and also for the patients with a significant element of psychogenic involvement by giving time to demystify symptoms.

EAACI/ENDA guideline strongly recommended that in confirmed LA allergy other LAs should be tested to identify an alternative. ${ }^{15}$ This is due to the possibility of cross-reactivity between LAs. Ester LAs are metabolized by plasmatic esterases with production of p-aminobenzoic acid (PABA), which is highly antigenic. Consequently, allergic reactions, are more frequent with ester compounds. In contrast, cross-reactivity between amides is less frequent and a specific pattern has not been identified. Recently, the aromatic ring meta-xylene, contained in most LAs (mepivacaine, lidocaine, and bupivacaine), but not in articaine (containing thiophene derivative) has been identified as a possible antigenic determinant. ${ }^{2}$ However, there are reports which do not support this hypothesis. ${ }^{21,31}$

We hereby demonstrated cross-reactivity within the amide group in three patients, though it is very rare. The first patient showed cross-reactivity between lidocaine and mepivacaine with good tolerance to prilocaine. The second patient, whose 
index reaction was with articaine, showed cross-reactivity between all three. Although all of the patients claimed an immediate-type past reaction, the third cross-reactive patient demonstrated an immediate-type IDT positivity with lidocaine but a delayed reaction with bupivacaine after SCPT, with good tolerance to mepivacaine and prilocaine. Likewise, another patient, whose immediate-type index reaction with articaine was observed in our clinic right away, presented with generalized erythema and urticaria after 12 hours of SCPT with lidocaine, but showed good tolerance to mepivacaine and prilocaine. Amide-type LAs have different metabolization routes ending with different metabolites. All those reactions within amide-type LAs, including immediate- and late-type reactions, do not seem to have a single pattern, so we hypothesize that maybe it is not cross-reactivity, but different sensitizations with more than one existing allergen structure other than the aromatic ring. For these reasons, we suggest that, although cross-reactivity among amide-type LAs is rare, in patients with hypersensitivity to one, tolerance to other drugs from this group should always be confirmed by performing a challenge test.

This study is limited by its retrospective design. Besides, many patients were unaware of the details of the index adverse drug reaction; so, there was a lack of identification of the actual specific LA. For the rest, either there was not a vasoconstrictor-free preparation of suspected LA or many of the patients did not give consent for a diagnostic test. As a result, a considerable portion of the examinations did not include challenges with the culprit LA compound. Although finding an alternative local anesthetic is valuable clinically in that it provides a treatment option, the risk of underestimating the true incidence of hypersensitivity to local anesthetics in these populations exists. Ideally, the primary goal of the provocation test should be to disprove allergy, not confirm.

\section{Conclusion}

1. Nowadays the main purpose of testing with LA is to disprove allergy and convince the patient and health professionals that they are not allergic. We believe that only the patients with a local anestheticinduced adverse drug reaction should be referred to an allergy clinic with appropriate consultation.

2. Within the group of patients with an alleged LA DHR, a history of generalized cutaneous symptoms and/or hypotension during the reaction may define subjects with an increased risk of LA allergy.
3. A stepwise test procedure may start with an undiluted LA SPT and IDT with 1/100 diluted LA especially for the patients with increased risk factors, and also for the patients with a significant element of psychogenic involvement by giving time to demystify symptoms.

4. We suggest that, although cross-reactivity among amide-type LAs is rare, in patients with hypersensitivity to one, tolerance to other drugs from this group should always be confirmed by performing a challenge test. Further studies are needed to investigate cross-reactivity both within drug types but also between type I and type IV allergy.

\section{Disclosure}

Kurtulus Aksu reports grants from AstraZeneca, GlaxoSmithKline, Sandoz, Abdi İbrahim, Chiesi, İbrahim Etem, and Novartis, outside the submitted work. The authors report no other potential conflicts of interest in this work.

\section{References}

1. Kvisselgaard AD, Mosbech HF, Fransson S, Garvey LH. Risk of immediate-type allergy to local anesthetics is overestimated-results from 5 years of provocation testing in a Danish allergy clinic. J Allergy Clin Immunol Pract. 2018;6(4):1217-1223. doi:10.1016/j. jaip.2017.08.010

2. Ing Lorenzini K, Gay-Crosier Chabry F, Piguet C, Desmeules J. Meta-xylene: identification of a new antigenic entity in hypersensitivity reactions to local anesthetics. J Allergy Clin Immunol Pract. 2016;4(1):162-164. doi:10.1016/j.jaip.2015.08.005

3. Milgrom P, Fiset L. Local anaesthetic adverse effects and other emergency problems in general dental practice. Int Dent J. 1986;36 (2):71-76.

4. Mook WH. XII.-Skin reactions to apothesin and quinin in susceptible persons. Arch Derm Syphilol. 1920;1(6):651-655. doi:10.1001/ archderm.1920.02350060032005

5. Volcheck GW, Mertes PM. Local and general anesthetics immediate hypersensitivity reactions. Immunol Allergy Clin North Am. 2014;34 (3):525-546, viii. doi:10.1016/j.iac.2014.03.004

6. Bhole MV, Manson AL, Seneviratne SL, Misbah SA. IgE-mediated allergy to local anaesthetics: separating fact from perception: a UK perspective. Br J Anaesth. 2012;108(6):903-911. doi:10.1093/bja/ aes162

7. Post TW, editor. Allergic Reactions to Local Anesthetics. Waltham, MA: UpToDate; 2020.

8. Fisher MM, Bowey CJ. Alleged allergy to local anaesthetics. Anaesth Intensive Care. 1997;25(6):611-614. doi:10.1177/0310057X970250 0602

9. Kvisselgaard AD, Krøigaard M, Mosbech HF, Garvey LH. No cases of perioperative allergy to local anaesthetics in the Danish anaesthesia allergy centre. Acta Anaesthesiol Scand. 2017;61(2):149-155. doi:10.1111/aas. 12833

10. Saito M, Abe M, Furukawa T, et al. Study on patients who underwent suspected diagnosis of allergy to amide-type local anesthetic agents by the leukocyte migration test. Allergol Int. 2014;63(2):267-277. doi:10.2332/allergolint.13-OA-0653 
11. Grzanka A, Wasilewska I, Śliwczyńska M, Misiołek H. Hypersensitivity lo local anesthetics. Anaesthesiol Intensive Ther. 2016;48(2):128-134. doi:10.5603/AIT.a2016.0017

12. Yilmaz I, Özdemir SK, Aydin Ö, Çelik GE. Local anesthetics allergy: who should be tested? Eur Ann Allergy Clin Immunol. 2018;50 (2):66-71. doi:10.23822/EurAnnACI.1764-1489.38

13. Harboe $T$, Guttormsen $A B$, Aarebrot $S$, Dybendal $T$, Irgens $A$, Florvaag E. Suspected allergy to local anaesthetics: follow-up in 135 cases. Acta Anaesthesiol Scand. 2010;54(5):536-542. doi:10.1111/j.1399-6576.2009.02193.x

14. Jacobsen RB, Borch JE, Bindslev-Jensen C. Hypersensitivity to local anaesthetics. Allergy. 2005;60(2):262-264. doi:10.1111/j.13989995.2005.00668.x

15. Brockow K, Garvey LH, Aberer W, et al. Skin test concentrations for systemically administered drugs - an ENDA/EAACI drug allergy interest group position paper. Allergy. 2013;68(6):702-712. doi:10.1111/all.12142

16. Trautmann A, Goebeler M, Stoevesandt J. Twenty years' experience with anaphylaxis-like reactions to local anesthetics: genuine allergy is rare. J Allergy Clin Immunol Pract. 2018;6(6):2051-2058.e2051. doi:10.1016/j.jaip.2018.04.005

17. Thyssen JP, Menné T, Elberling J, Plaschke P, Johansen JD. Hypersensitivity to local anaesthetics-update and proposal of evaluation algorithm. Contact Dermatitis. 2008;59(2):69-78. doi:10.1111/ j.1600-0536.2008.01366.x

18. Furci F, Martina S, Faccioni P, Faccioni F, Senna G, Caminati M. Adverse reaction to local anaesthetics: is it always allergy? Oral Dis. 2020;26(6):1340-1342. doi:10.1111/odi.13310

19. Eggleston ST, Lush LW. Understanding allergic reactions to local anesthetics. Ann Pharmacother. 1996;30(7-8):851-857. doi:10.1177/ 106002809603000724

20. Domínguez-Ortega J, Phillips-Angles E, González-Muñoz M, Heredia R, Fiandor A, Quirce S. Allergy to several local anesthetics from the amide group. J Allergy Clin Immunol Pract. 2016;4 (4):771-772. doi:10.1016/j.jaip.2016.02.009

21. De Pasquale TMA, Buonomo A, Pucci S. Delayed-type allergy to articaine with cross-reactivity to other local anesthetics from the amide group. J Allergy Clin Immunol Pract. 2018;6(1):305-306. doi:10.1016/j.jaip.2017.07.046
22. Bousquet $\mathrm{J}$, Heinzerling $\mathrm{L}$, Bachert $\mathrm{C}$, et al. Practical guide to skin prick tests in allergy to aeroallergens. Allergy. 2012;67(1):18-24. doi:10.1111/j.1398-9995.2011.02728.x

23. Brockow K, Romano A, Blanca M, Ring J, Pichler W, Demoly P. General considerations for skin test procedures in the diagnosis of drug hypersensitivity. Allergy. 2002;57(1):45-51.

24. Astarita C, Gargano D, Romano C, et al. Long-term absence of sensitization to mepivacaine as assessed by a diagnostic protocol including patch testing. Clin Exp Allergy. 2001;31(11):1762-1770. doi:10.1046/j.1365-2222.2001.01226.x

25. Haddi E, Charpin D, Tafforeau M, et al. Atopy and systemic reactions to drugs. Allergy. 1990;45(3):236-239. doi:10.1111/j.13989995.1990.tb00489.x

26. Zuberbier T, Aberer W, Asero R, et al. The EAACI/GA2LEN/EDF/ WAO guideline for the definition, classification, diagnosis and management of urticaria. Allergy. 2018;73(7):1393-1414. doi:10.1111/ all.13397

27. Phillips JF, Yates AB, Deshazo RD. Approach to patients with suspected hypersensitivity to local anesthetics. Am J Med Sci. 2007;334(3):190-196. doi:10.1097/MAJ.0b013e3181406001

28. Wasserfallen JB, Frei PC. Long-term evaluation of usefulness of skin and incremental challenge tests in patients with history of adverse reaction to local anesthetics. Allergy. 1995;50(2):162-165. doi:10.1111/j.1398-9995.1995.tb05074.x

29. McClimon B, Rank M, Li J. The predictive value of skin testing in the diagnosis of local anesthetic allergy. Allergy Asthma Proc. 2011;32(2):95-98. doi:10.2500/aap.2011.32.3417

30. Specjalski K, Kita-Milczarska K, Jassem E. The negative predictive value of typing safe local anesthetics. Int Arch Allergy Immunol. 2013;162(1):86-88. doi:10.1159/000350763

31. González-Delgado P, Antón R, Soriano V, Zapater P, Niveiro E. Cross-reactivity among amide-type local anesthetics in a case of allergy to mepivacaine. J Investig Allergol Clin Immunol. 2006;16 (5):311-313.

\section{Publish your work in this journal}

The Journal of Asthma and Allergy is an international, peer-reviewed open-access journal publishing original research, reports, editorials and commentaries on the following topics: Asthma; Pulmonary physiology; Asthma related clinical health; Clinical immunology and the immunological basis of disease; Pharmacological interventions and new therapies. The manuscript management system is completely online and includes a very quick and fair peer-review system, which is all easy to use. Visit http://www.dovepress.com/testimonials.php to read real quotes from published authors. 